\title{
A Tentative Model for the Documentation and Monitoring of Historic Streets by Mobile Digital Application - A Case Study of Kunming Nanqiang Street
}

\author{
SHANG Jin ${ }^{\text {a }} *$, WU Qilin ${ }^{\text {a }}$, ZHANG Jie ${ }^{\text {a }}$ \\ ${ }^{a}$ Research Centre for Historic and Cultural Cities of National Importance, Tsinghua Tongheng Urban Planning and Design Institute, \\ 100085 Beijing, China - (shangjin, wuqilin, zhangjie)@thupdi.com
}

\section{Commission VI, WG VI/1}

KEY WORDS: Documentation and Monitoring, Historic Streets, Mobile Digital Application

\begin{abstract}
:
Conservation planning for historic streets, where heritage preservation and the modernization of life converge, has been playing a fundamental role. As technology is increasingly changing every aspect of our contemporary life, conservation is also blessed with new opportunities, and how to enhance the effectiveness of the plans by means of emerging technological measures is a new question. Starting from the conservation of Kunming Nanqiang Historic Street, a tentative model for an integrated mobile application is proposed based considerations of the user demands from conservation planner, property manager, tenant and visitor. Tentative applications include heritage interpretation and presentation, enhanced visitor experience, and management system, which are to build up an innovative chain of "heritage research - management planning - digital support" for the purpose of community revitalization.
\end{abstract}

\section{INTRODUCTION}

Technological advancement has become a major driver of the sustainable development for cultural heritage conservation. How to integrate new technologies with traditional conservation planning for the conservation and development of historic streets is a significant question to be answered in this new era. From this perspective, a hypothetical model of "heritage research - management planning - digital support" can be constructed by means of digital measures. With research on the heritage values of historic streets as the basis, digital applications on mobile devices can collect data to inform decision-making as regards the conservation, management and development of historic streets, which demonstrates the effectiveness of management planning with concrete data. In such context, a model that facilitates the digitally-aided integration of "research, management and use, and community revitalization" is proposed based on the conservation of Nanqiang Street in Kunming, China.

\section{NANQIANG HISTORIC STREET AND ITS CONSERVATION PLANNING}

Nanqiang Street in the southern part of Kunming city has been a business area with various trades since $17^{\text {th }}$ century. Jewels, jade, felt, timber and bamboo were among the most popular goods and even Hakkas from Jiangxi and Canton established their guilds here. As a major foreign trade center known as Silk Road in the Southwest, Emperor Guangxu approved of foreign residence and business in 1905, making Kunming one of the first cities open to foreign trades. Such historic background bequeathed Nanqiang Street of rich culturally significant features. The "Nanqaing Street Historic Area Conservation Plan", developed in 2012 on the principles of authenticity and integrity and sustainable use, describes the Street as a characteristic area that preserves the historic urban fabric and townscape, as well as traditional and contemporary business. By 2014, implementation of the Plan has been steadily progressing, and a next question is how to further revitalize the area and inform the planners with the results.

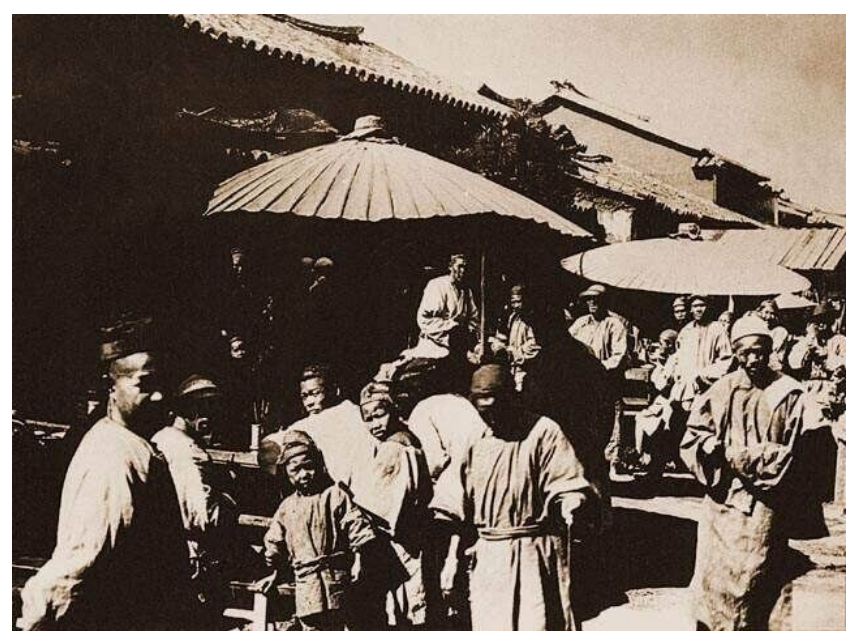

Figure 1. Nanqiang Street, Late Qing Dynasty (Source: http://www.7c6u.cn/0911/1961.html)

* Corresponding author. 


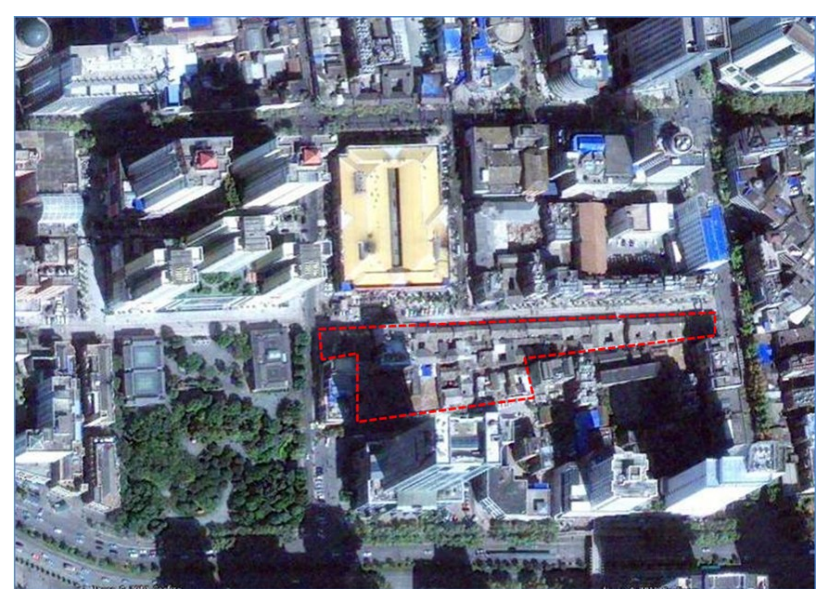

Figure 2. Nanqiang Street, present day

\section{USERS AND DEMANDS}

A digital model that facilitates the "research, management and use, and community revitalization" of Historic Streets should put the potential users and their demands in the first place, which is presumably categorized into four groups:

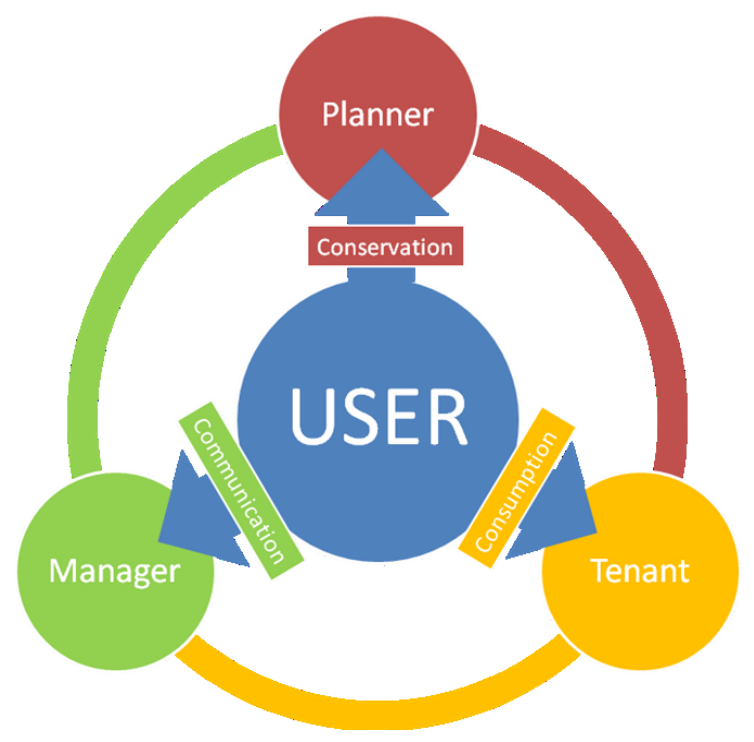

Figure 3. User-Demand Diagram

\subsection{Conservation Planners}

Professional planning institution and planners, responsible for developing conservation plans for historic areas, best understand their values and take their conservation and monitoring as a priority. The monitoring of the streetscape, façade, and visitor dynamism is critical for preserving the character and values of the area, which is indicated in the Plan.

\subsection{Property Manager}

The manager of Nanqiang Street focuses on the sustainable development and property appreciation on top of conservation. Visitor capacity, stay time, behaviour and preference are vital to inform decision-making as regards property management. A better understanding of the relationship between the visitors and the physical features will enhance management efficiency to an optimal level.

\subsection{Tenants}

Tenants of the property who run their business in the historic area seek maximized promotion. In addition to a boost from the historic environment, e-business can play a significant role in communicating the cultural values of the property via online shops and product display, as well as promotion and cultural events. Interfaces to other e-business platforms can have multiplying effects.

\subsection{Visitors}

Visitors are consumers of the historic and cultural contents of the area as well as contemporary cultural and creative products. Interpretation and dissemination of the values, combined within tour guide and e-services, will revitalize the local community by attracting more visitors.

\section{TENTATIVE APPLICATIONS}

Based on the identification of users and their respective demands, a technology roadmap can be developed. From the wide availability of contemporary digital applications, the gap between heritage and human interaction can be effectively bridged by technology. A fundamental goal is to provide different data to different users. For example, smart tour guide, event update and itinerary recommendation can greatly enhance visitor experience. Documentation of visitor behaviour by means of electronic labelling, wireless Bluetooth, and mobile communications will then generate data for analysis of their preferences and interests that can inform both the planners and managers. The digital model therefore basically includes a mobile application and a control panel. The former collects data from the visitors, and the latter analyzes the data for the planners, managers and tenants.

\subsection{Heritage Interpretation and Presentation}

The digital model can facilitate heritage interpretation and presentation more effectively than traditional graphic media. Metric survey, historic maps and photos, point clouds, and reconstructions can be integrated with textual documents, oral history and intangible heritage. Major modules include:

4.1.1 Interactive Map: Documents collected during the valorisation process of Nanqiang Street can be integrated into one interactive map that demonstrates its evolution in a dynamic manner. Comparison of the historic fabric with contemporary reality will intuitively reveal key changes for the visitors on a smart phone. When georeferenced, they can easily understand whether or not they are standing on significant historic features. 


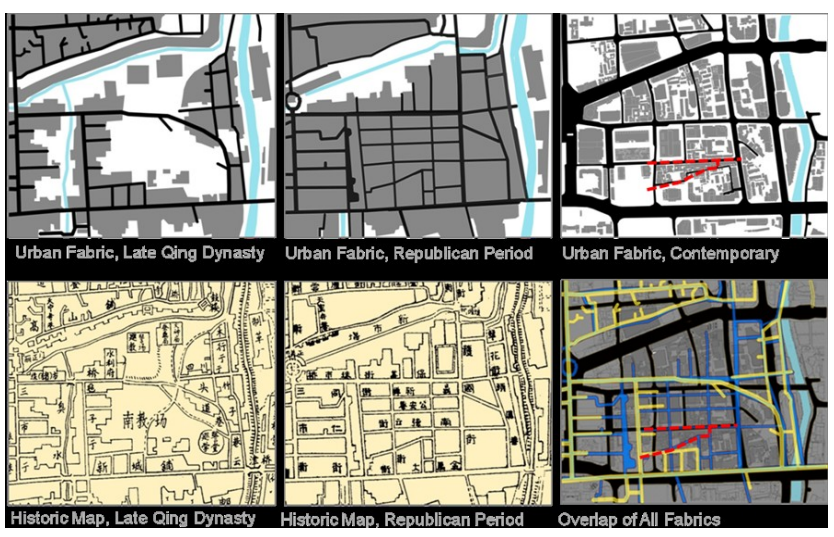

Figure 4. Historic Maps and Urban Fabrics of Nanqiang Street

4.1.2 Historic Streetscape: Historic photos showing nonexistant features best illustrates the values of Historic Streets. Visitors can be encouraged to take photos at specific positions where historic photos are available. This module not only motivates public participation but also generates a contemporary documentation of the area for the future. The most visited place will inform the planner and manager of public interests.
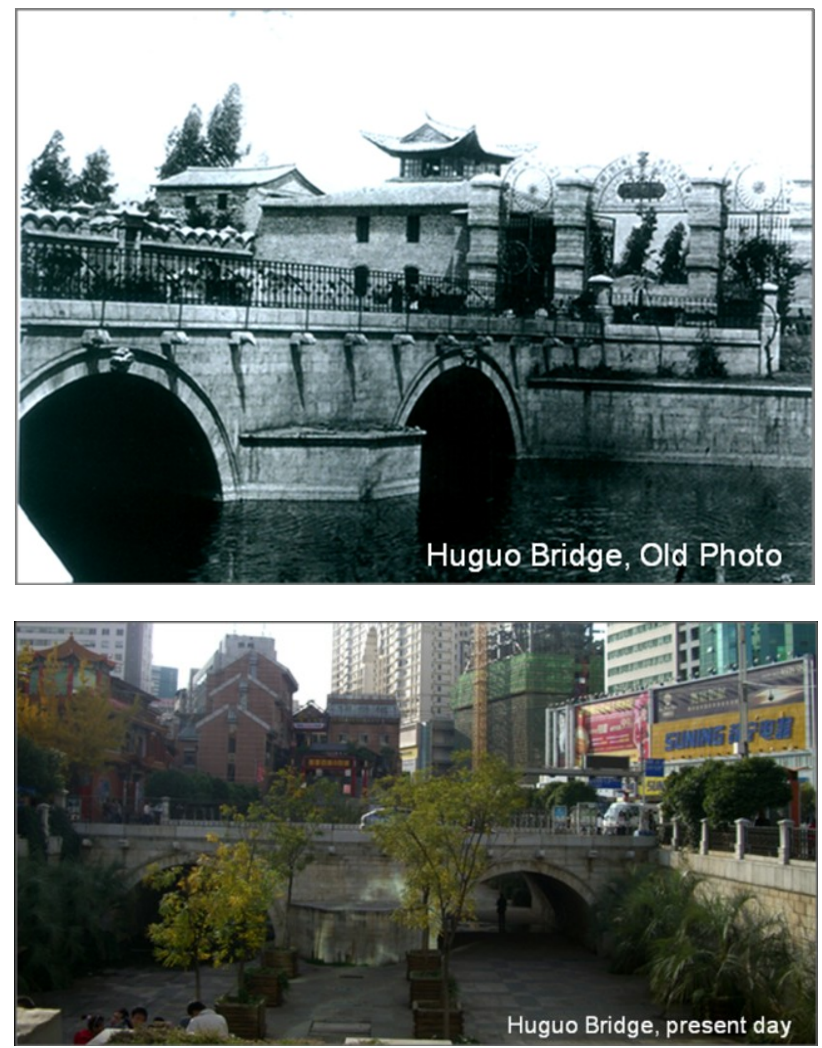

Figure 5. Historic and Contemporary Photos of

Places of Interest
4.1.3 Building Restoration: Historic buildings in Nanqiang Street documented with modern means can further demonstrate the value of restorations as in the Plan. For example, captured point clouds can be used to create 3D virtual tours of significant structures for visitors in a 360-degree panorama. Each point of reference with regards to restorations can be interpreted with embedded captions in the model, while expert visitors can add comments. In this way, feedbacks from professional are collected to inform the planners.
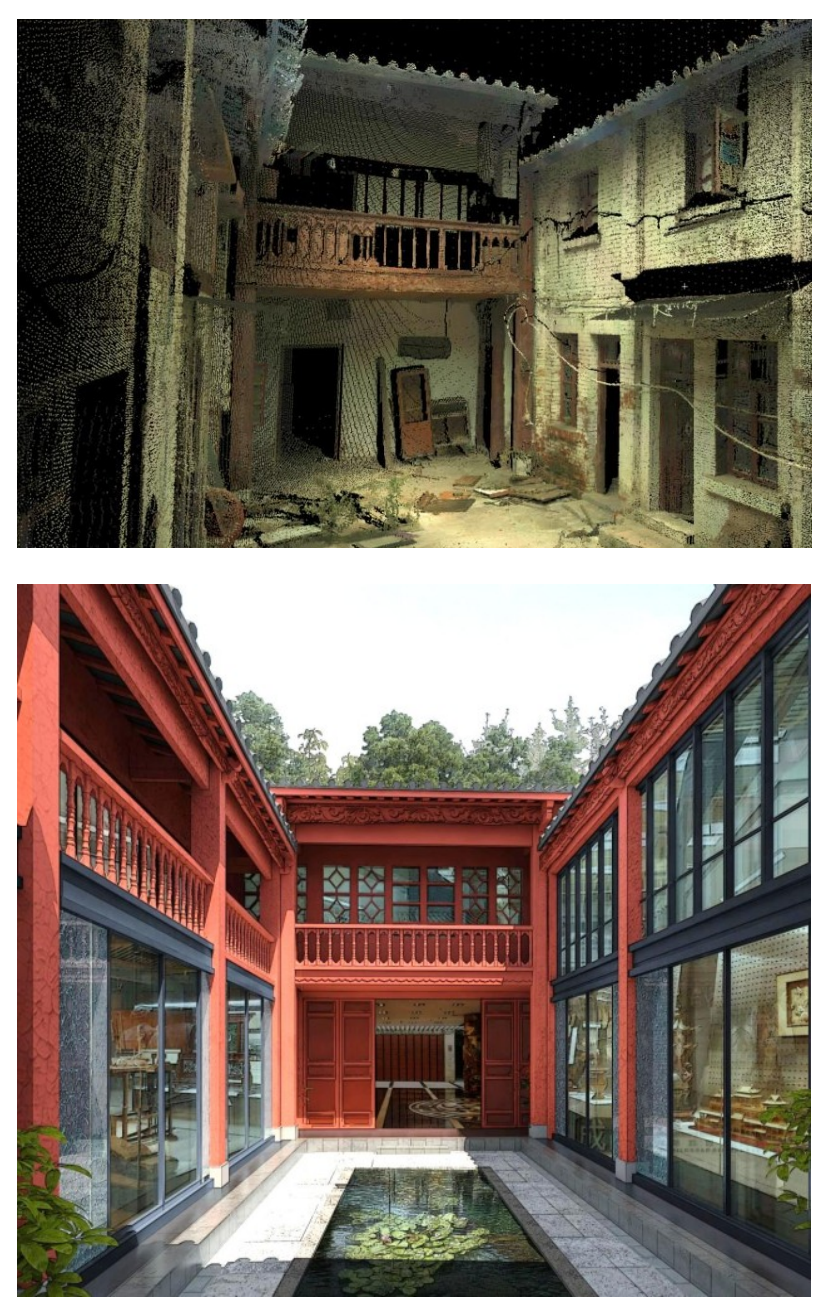

Figure 6. Historic Building and Renovation Design

\subsection{Enhanced Visitor Experience}

The mobile application is mainly targeted at visitors who provide the managers with data in various forms. 

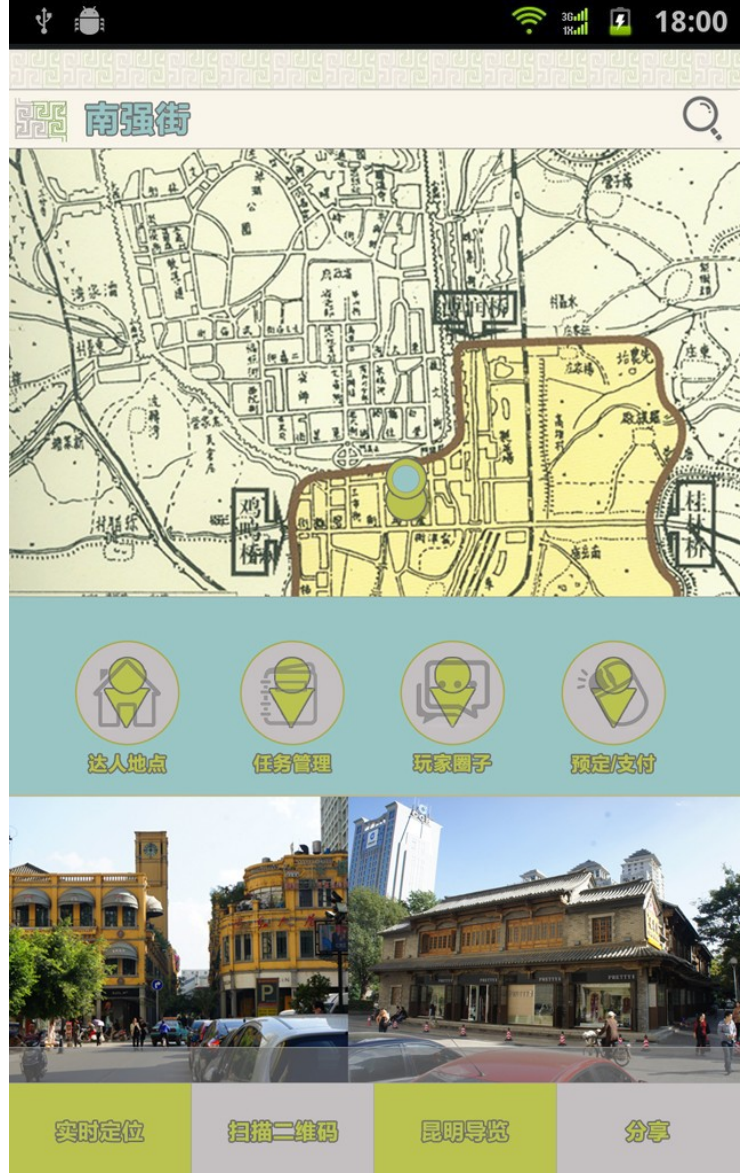

Figure 7. Tentative UI Design

4.2.1 Useful Information: Visitors will be notified of the closest service available in the Street by georeferenced alert. For example, visitors will know it when a restaurant has a new course on promotion. Throughout the year, managers will learn of their visitors' food preferences and lease the property to more welcome tenants. As for cultural events, local and visitor participants can reserve their place digitally so that managers will have a better of idea of the most popular type.

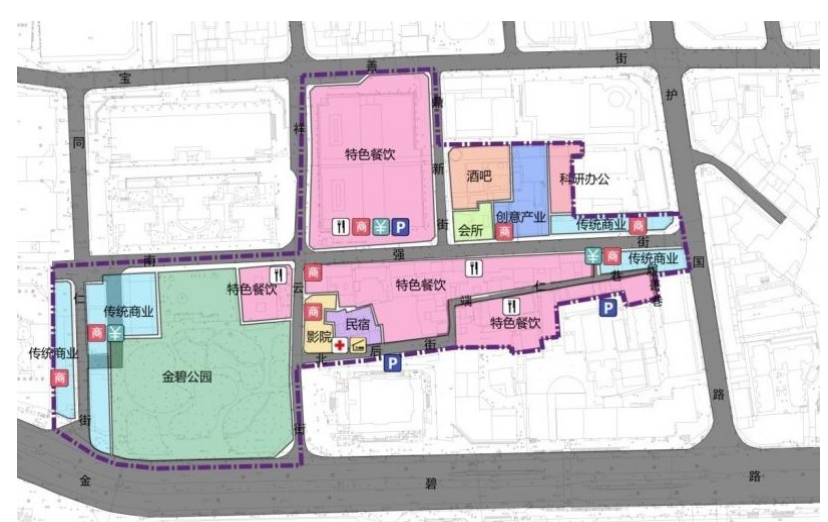

Figure 8. Services Mapped in the Historic Street
4.2.2 Friend-finding and Cultural Games: Visitors' preferences can also be used to find friends of similar interests. They can choose to team up for cultural games in the Street, like visiting all the designated built heritage in the Street by photographing them with their smart phone. Group reenactment of historic events like the Peacock Gall assassination can be another way to enhance collective memory by means of online organization. Participation feedbacks will then provide managers with further guidance.

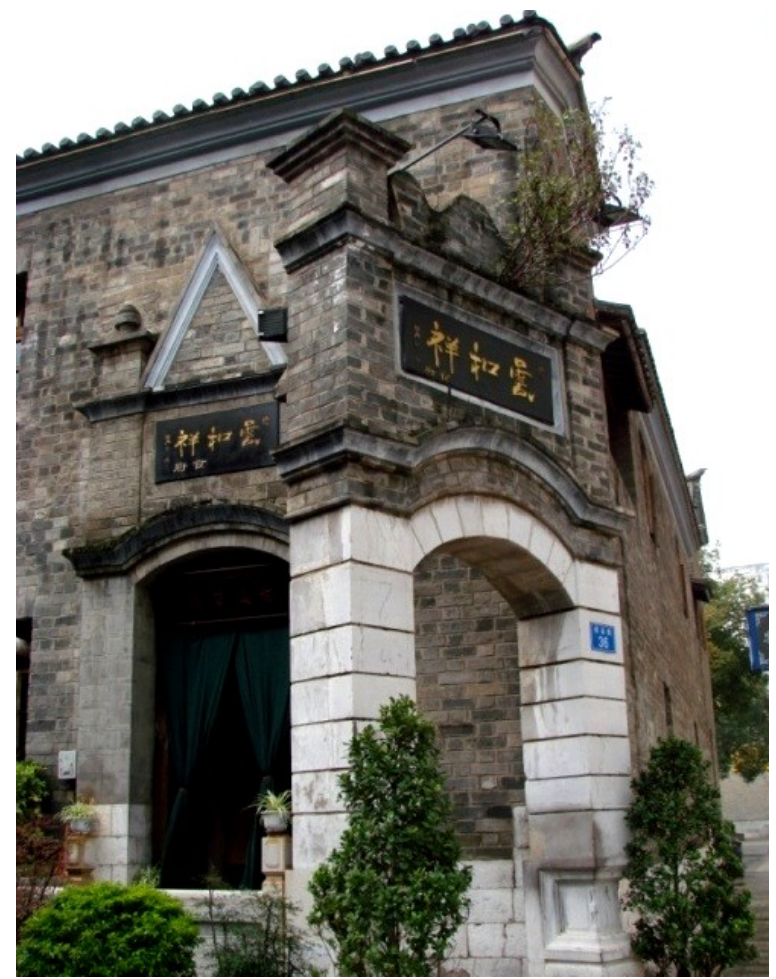

Figure 9. Historic Landmark as Cultural Destination

4.2.3 E-business Platform: Visitors may view courses or products and pre-order on the smart phone via interfaces to other e-business and online transaction service before getting to the destination, and then give ratings.

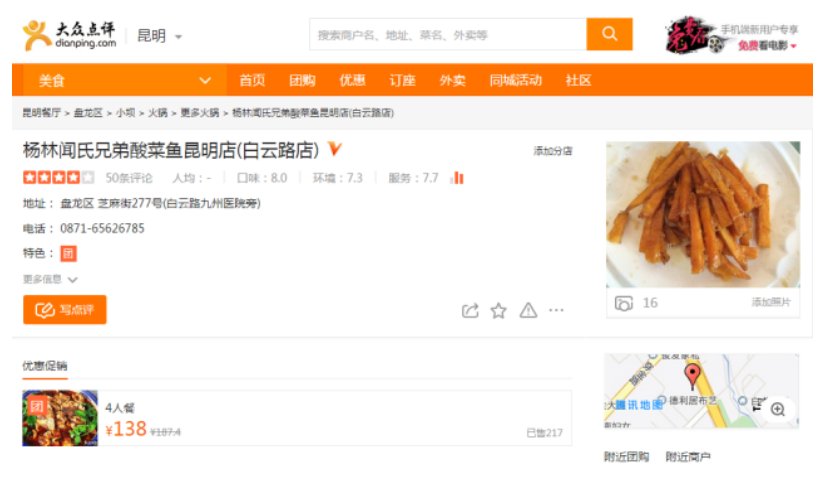

Figure 10. Typical E-Restaurant Platform in China, to be connected with mobile application 


\subsection{Management System}

The management system processes the data collected from the visitors and informs planners, managers, and tenants with differentiated accesses.

4.3.1 Conservation Monitoring: A benchmark condition is established by the planners during their initial field investigation of the Street. Dynamic inputs from various user activities documented from the mobile application will facilitate monitoring of heritage condition and visitor capacity. For example, if a visitor has uploaded a new photo showing certain structures significantly differing from the benchmark, intervention will be suggested. For another, warnings can be triggered on the smart phones if visitor number reaches a critical level to ensure the safety of both the people and buildings.

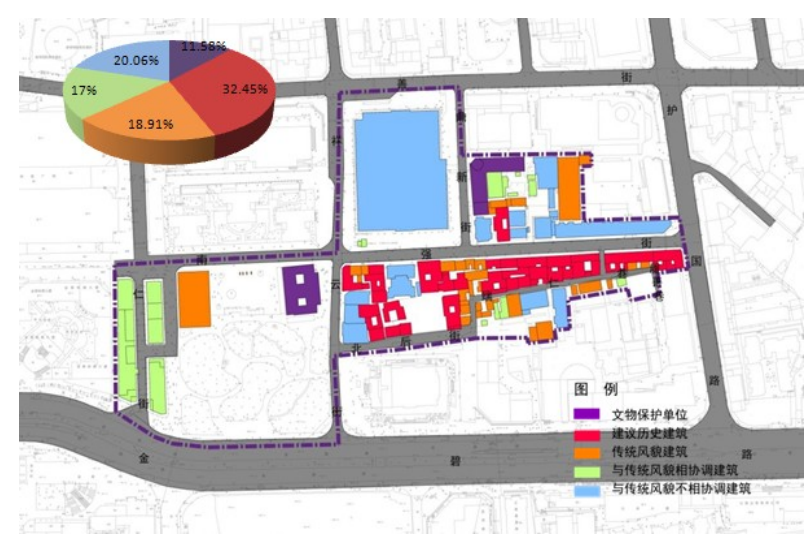

Figure 11. Mapping of Historic Structures of Different Values

4.3.2 Property Management: Statistics of the tenants' sales and performances, like visitors stay time, purchase type and preferences, will be used to generate reports for the property manager to organize the whole area more efficiently.

4.3.3 Tenant Platform: Tenants also have access to general statistics which gives them better idea of what is more popular at a certain time. This will be one way to encourage competitiveness for the community.

\section{CONCLUDING REMARKS}

The tentative model of "heritage research - management planning - digital support" has been proposed for the digital enhancement of Historic Street conservation, which is an innovative approach to apply leading technologies to heritage conservation. Tentative applications are designed for the major users of conservation planners, property managers, tenants and visitors considering their potential demands respectively. Technological measures will facilitate heritage interpretation and presentation, enhanced visitor experience, property management to achieve "research, management and use, and community revitalization" supported by dynamic field data. Despite of comprehensive considerations of the digital model, a real application is required in the next phase to prove its effectiveness and advantages.

\section{REFERENCES}

ZHANG Gong, HUO Xiaowei, ZHANG Jie, 2011. A Mobile GIS-based Digital Information System for Traditional Buildings in Historic and Cultural City, Town, Village and Street. In: 2011 Annual National Planning Conference Proceedings.

LONG Ying, MAO Qizhi, DANG Anrong, 2009. Beijing Urban Development Model: Urban Growth Analysis and Simulation Tsinghua Science and Technology. In: Tsinghua Science and Technology.

SHAN Jixiang, 2008. A Dialectic Reflection of the Development in Cultural Heritage Conservation Science and Technology. In: Museum International (Chinese Edition).

ZENG Chunjing, LUO Jiaming, GUO Zhan, 2008. Issues Concerning the Technical Standards for World Heritage Monitoring. In: China Cultural Heritage.

GUO Huadong, 2014. Promotion of Spatial Technology in the Smart Management of UNESCO World Heritage List. In: World Heritages.

Wun-Bin Yang, Ya-Ning Yen, Hung-Ming Cheng, 2012. An Integrated Management System for Historical Buildings: The Case Study of Dihua Historical Street Districts in Taiwan. In: Progress in Cultural Heritage Preservation, Springer Berlin Heidelberg.

LI Gongli, SHANG Jin, CHEN Huilian, 2013. A Mobile Application for Virtual Heritage and UGC Public Sharing. In: ISPRS Annals of the Photogrammetry, Remote Sensing and Spatial Information Sciences, Volume II-5/W1, 2013

Hugh Denard and Drew Baker, Anna Bentkowska-Kafel, 2012. Paradata and Transparency in Virtual Heritage (Digital Research in the Arts and Humanities), Ashgate London. 